\title{
EXPERIMENTAL STUDY AND THEORETICAL ANALYSIS ON SEISMIC PERFORMANCE OF CASTELLATED BEAM WITH HEXAGONAL HOLES
}

\author{
Lian-Guang Jia *, Ran Bi, Yu-Xiao Lang and Xue-Feng Li \\ School of Civil Engineering, Shenyang Jianzhu University, Shenyang 110168, China. \\ *(Corresponding author: E-mail: syjlg@163.com)
}

\section{A B S T R A C T}

Under a reciprocating load, through an experimental study and finite element analysis, the effect of different arrangements of stiffening ribs on the failure mode, local stability, and hysteretic performance of castellated beams with hexagonal holes is investigated. The test specimens comprise four steel castellated beams, two of which are reinforced with transverse stiffening ribs having the same opening rate but different height-to-thickness ratios of the webs; the two other steel castellated beams do not have any stiffening ribs. The results show that the steel castellated beams with a high height-to-thickness ratio are prone to local buckling failure of the webs. When, under a low-cycle reciprocating load, the transverse stiffening ribs are arranged, and the steel castellated girder is constrained by the plane, the failure mainly occurs at the hole angle position, and the hysteretic performance of the steel castellated girder is obviously improved compared with the non-stiffened steel castellated beam. Using finite element analysis, we realize that different arrangements of transverse stiffening ribs change the failure mode of the steel castellated beam and that the reasonable arrangement of the stiffening ribs has a significant influence on the hysteretic performance of the castellated beam.

A R T I C LE H IS T O RY

$\begin{array}{ll}\text { Received: } & \text { 24 June } 2019 \\ \text { Revised: } & \text { 12 May } 2020 \\ \text { Accepted: } & \text { 30 May } 2020\end{array}$

\section{K E Y W O R D S}

Castellated beam;

Hysteretic performance;

Experimental study;

Transverse stiffening ribs;

Finite element analysis;

Failure mode

\section{Introduction}

The castellated beams are formed by dislocated welding after cutting out certain geometrical patterns from the webs of H-beam members. As a result, the section height of the beams increases, and their flexural stiffness improves significantly. Moreover, the web openings allow the pipeline equipment to pass easily. However, the height-to-thickness ratio of the web is increased, which may lead to the local instability under loading; the seismic performance of the local buckling of the castellated member webs especially may be severely affected by the earthquake. Steel castellated girder webs have a variety of local buckling modes [1] such as the buckling of piers and bridges due to shear, bending, compression, local concentration force, and so on [2]. Therefore, the focus of recent research has been on the strength and local buckling of the perforated webs. To popularize the application of castellated beams, to avoid the structural failure caused by the buckling of the webs, and to meet the requirements of seismic structures, the arrangement of stiffening ribs in the holes of the castellated beams has become an important structural measure in some building structures.

Various scholars have focused on the static performance of the local stability of castellated beams. For example, R. Feng [3] carried out bending tests on 12 specimens and compared the calculated bending strength according to the standards of various countries; they found that the American National Standard and the North American Code are relatively conservative, while the European Code 3 is not so conservative. In another work, Xianhui Li [4] theoretically analyzed the critical buckling capacity of composite beams and proposed a prediction formula for the critical buckling capacity of composite beams and validated the formula by experimental data. Chen D. Y. et al. [5-7] examined the elastic critical buckling load of honeycomb beams and showed that transverse stiffeners could significantly improve their buckling resistance. Besides, Jia L.G. [8-10] studied the shear bearing capacity of honeycomb beams under different conditions and reported that the shear bearing capacity of the beams is greatly affected by flange thickness, opening ratio, and pass type; they also proposed a simplified formula for calculating shear bearing capacity and presented a correlation between bending and shear. Some other relevant works in this context can also be found elsewhere [11-13].

Although researches have mostly focused on the static performance, including the shear and buckling capacity, of honeycomb beams, some works have also analyzed the seismic performance of honeycomb beams and examined the impact of different factors on the hysteretic performance of these beams. For solid web beams, setting up transverse stiffeners increases the dead weight of the beams and wastes steel, so using stiffeners in steel honeycomb beams can be a significant area of research; indeed, little research has been conducted into the subject. Therefore, this paper considers a regular honeycomb beam with hexagonal openings under six regular reciprocal loads as the research object and adopts the method of combining theoretical analysis with experimental research to study the hysteretic behavior of steel honeycomb beams under low-cycle reversed loading; we also investigate the effect of the arrangement of the transverse stiffening ribs on improving the bearing capacity, stiffness, ductility, and energy dissipation of steel honeycomb beams.

\section{Experimental study}

\subsection{Test specimens}

The dislocation welding method was employed to produce the hexagonal castellated beams. The steel castellated beam is loaded in the middle, and to avoid the local buckling failure, two symmetrical transverse stiffeners with the same material as the beam and with a thickness of $14 \mathrm{~mm}$ were welded in the middle. A steel castellated beam with the transverse stiffener led to a thickness of $6 \mathrm{~mm}$ symmetrically in the position of the pier plate. One plate containing six openings was welded to the ends of all the specimens to be fixed to the bearing with bolts. Two groups, each including two specimens, were designed; in the first group, the web thickness is changed to vary the height-to-thickness ratio of the web and to study the destruction form and hysteretic performance of the castellated beams. The second group investigates the effect of setting up transverse stiffeners. The model of the test specimen along with the related dimensions is presented in Fig. 1, and Table 1 lists the specific dimensions of the steel castellated beams.

\subsection{Material performance test}

Q355B grade steel was selected, and its yield strength (fy), ultimate strength (fu), and elastic modulus (E) were measured. The tensile specimens were sampled from the base metal according to the requirements described in ref [14], and two plates with a thickness of 6 and $8 \mathrm{~mm}$ were selected. Three tensile specimens were prepared and analyzed to obtain the average mechanical properties of each sample. The dimensions of the standard tensile specimen are presented in Fig. 2. Then, according to the conditions reported in ref [15], the standard tensile specimen was processed. Using the yield and ultimate loads of the specimen recorded by the tensile machine, the yield strain of the specimen measured by the resistance strain gauge and the cross-sectional area of the actual test specimen. The tensile test results are tabulated in Table 2. 
Cross-sectional dimensions of the castellated beams

\begin{tabular}{cccccc}
\hline & Beam ID & Sectional dimension & Hole height (mm) & Height-to-thickness ratio & Opening ratio $(\%)$ \\
\hline \multirow{2}{*}{1} & FWL-240-85 & $400 \times 200 \times 4.5 \times 8$ & 240 & 240 & 85 \\
& FWL-240-75 & $400 \times 200 \times 5.1 \times 8$ & 240 & 60 \\
6 & JJFWL-240-85 & $400 \times 200 \times 4.5 \times 8$ & 240 & 75 \\
\hline
\end{tabular}

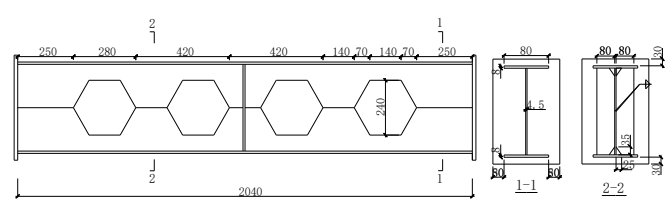

FWL-240-85

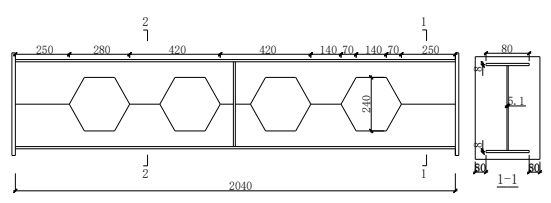

FWL-240-75

(a) Steel castellated beam

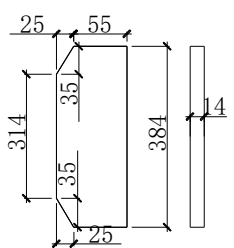

Middle stiffening rib

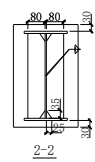

$\underline{2-2}$

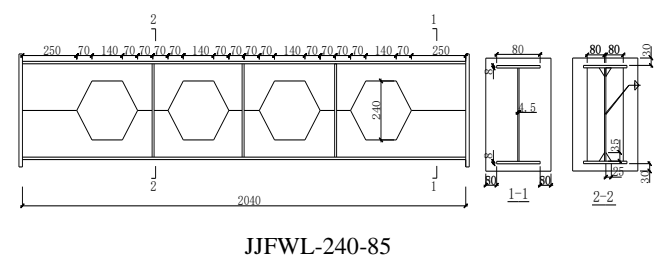

JJFWL-240-85

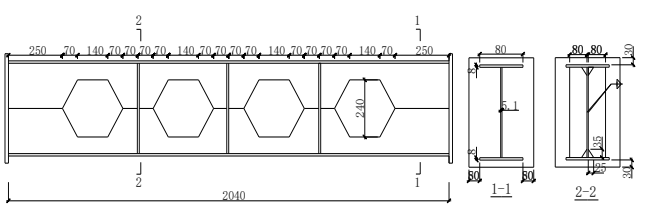

JJFWL-240-75

(b) Steel castellated beam with transverse stiffeners

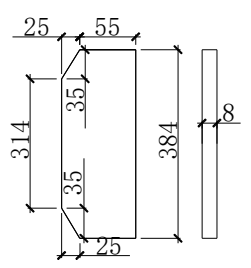

web stiffening rib

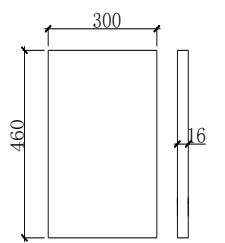

wallboard

(c) Stiffening ribs and end plate

Fig. 1 A sketch map of the castellated beams
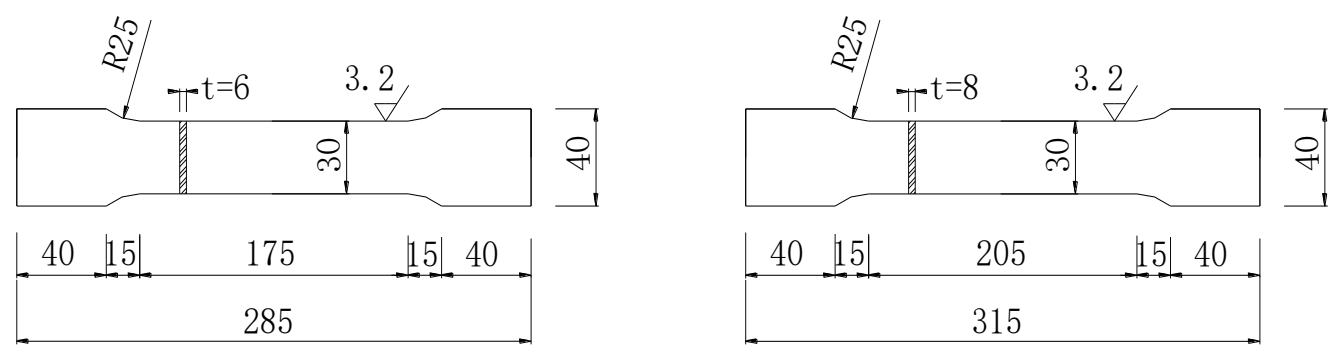

Fig. 2 Standard specimen for tensile testing

Table 2

Mechanical properties of steel

\begin{tabular}{|c|c|c|c|c|}
\hline Specimen specification & Specimen ID & $f_{y}\left(\mathrm{~N} / \mathrm{mm}^{2}\right)$ & $f_{u}\left(\mathrm{~N} / \mathrm{mm}^{2}\right)$ & $E\left(10^{5} \mathrm{~N} / \mathrm{mm}^{2}\right)$ \\
\hline \multirow{4}{*}{$6 \mathrm{~mm}$} & $6-1$ & 368.3 & 521.5 & 2.09 \\
\hline & $6-2$ & 338.5 & 510.5 & 2.03 \\
\hline & $6-3$ & 347.4 & 508.4 & 2.11 \\
\hline & Average value & 351.4 & 513.5 & 2.08 \\
\hline \multirow{4}{*}{$8 \mathrm{~mm}$} & $8-1$ & 368.5 & 544.5 & 1.96 \\
\hline & $8-2$ & 364.6 & 549.6 & 1.93 \\
\hline & $8-3$ & 360.7 & 547.3 & 2.04 \\
\hline & Average value & 364.6 & 547.1 & 1.98 \\
\hline
\end{tabular}

\subsection{Test equipment and loading system}

The experiments were conducted at the Structural Engineering Laboratory of SJZU University using the designed test device schematically shown in Fig. 3 . In order to ensure the stability of the steel castellated beam, two lateral supports are arranged at 1/4 and 3/4 length of the beam. The image of the actual device is displayed in Fig. 4. To ensure that both ends of the beam do not move up and down and that they can be effectively rotated, we designed 
three one-way hinges and a sliding box as a support bearing connection as depicted in Fig. 5. The left end plate of the specimen is connected to the fixed pier by high strength bolts to form the hinge support. The right end plate of the specimen is fixed to the hinge device by high strength bolts and connected with the sliding box to form a sliding hinge bearing. The sliding box uses three rollers on top and bottom and is placed on the groove of the welded plate. A pair of lateral supports are arranged on both sides of the specimen to ensure the stability of the test component in the process of loading.

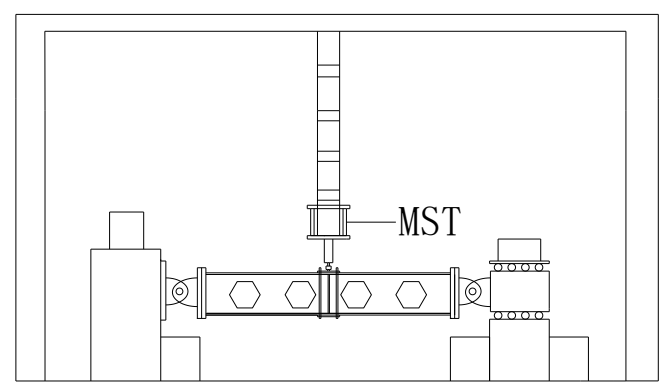

Fig. 3 A sketch of the loading device

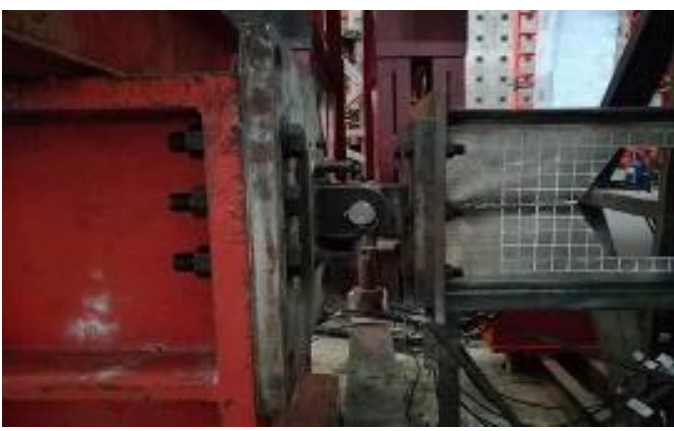

(a) Hinged support

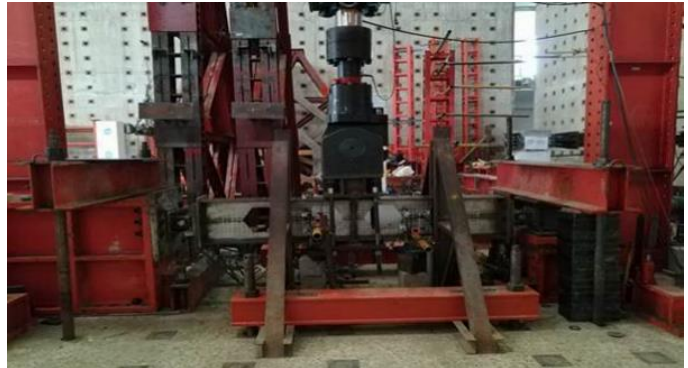

Fig. 4 Test loading device

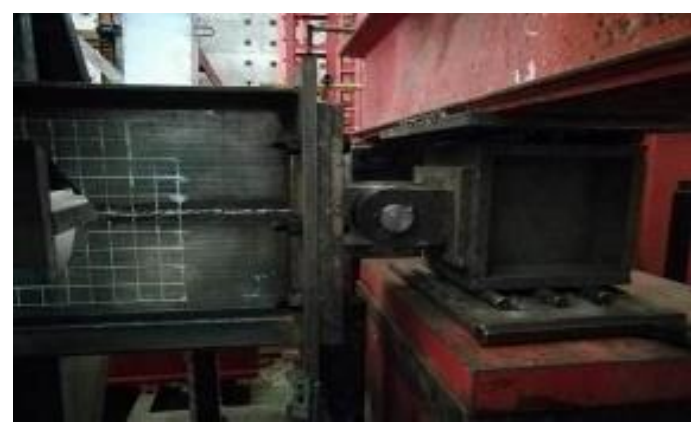

(b) Sliding support

Fig. 5 Support connection device

According to the Specification for Seismic Test of Buildings [16], the load-displacement double-control method is employed for the loading of the quasi-static test. By preloading, we can ensure that the beam suitably contacts the loading point before loading. The stability and reliability of the test equipment is checked, and we ensure that the observation instrument operates normally; then, the initial value of each instrument is recorded. The load-displacement control method is divided into two stages. The beam is loaded by $20 \mathrm{kN}$ in the elastic phase using load control, and each stage is cycled once until the specimen yields. When the beam yields, the displacement control is used to load it, and the yield displacement $\left(\Delta_{\mathrm{y}}\right)$ is increased by $0.5 \Delta_{\mathrm{y}}$; each stage is cycled twice until the specimen is destroyed or the bearing capacity reaches the limit load of $85 \%$ or less. The loading process is shown in Fig. 6 .

During the whole experiment, we observe the deformation and failure of the member and record the order of the damage location and the corresponding loading level. Furthermore, we should ensure that there is no external barrier to the movement of the structural member during the loading process, and there is enough space for the deformation of the beam. The test should be terminated if the plane instability occurs.

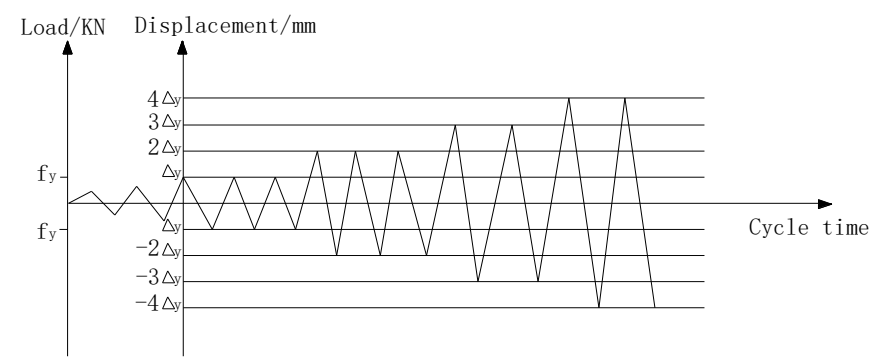

Fig. 6 Loading process of the beam

\subsection{Measurements}

\subsubsection{Displacement measurement}

To study the local buckling deformation of the web of the steel castellated beam, a displacement meter is placed in the web position of the beam to measure the web displacement. It should be noted that in case of using transverse stiffeners, the displacement meter is no longer placed in the web position of the beam. Displacement meters 1,2,3, 4, and 6 are $50 \mathrm{~mm}$, and displacement meter 5 is $100 \mathrm{~mm}$. To calculate the real deflection of the castellated specimen, the effect of beam-end slip must be eliminated by subtracting the cross-middle displacement from the support displacement. The arrangement of the displacement meters and numbering the hole angles are presented in Fig. 7.

\subsubsection{Strain measurement}

To study the influence of the openings on the flange stress, double rows of strain gauges were arranged at the upper and lower positions of the flange. Then, we arranged the strain flowers at the hole angle and the strain gauges in the position of the pier plate to study the variation of the stress in the position between the pier plate and the hole. The layout of the steel castellated beam is shown in Fig. 8.

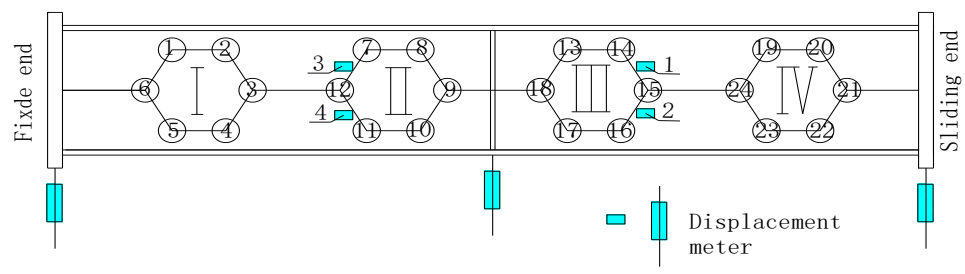

Fig. 7 Arrangement of displacement meters and numbering the hole angles 

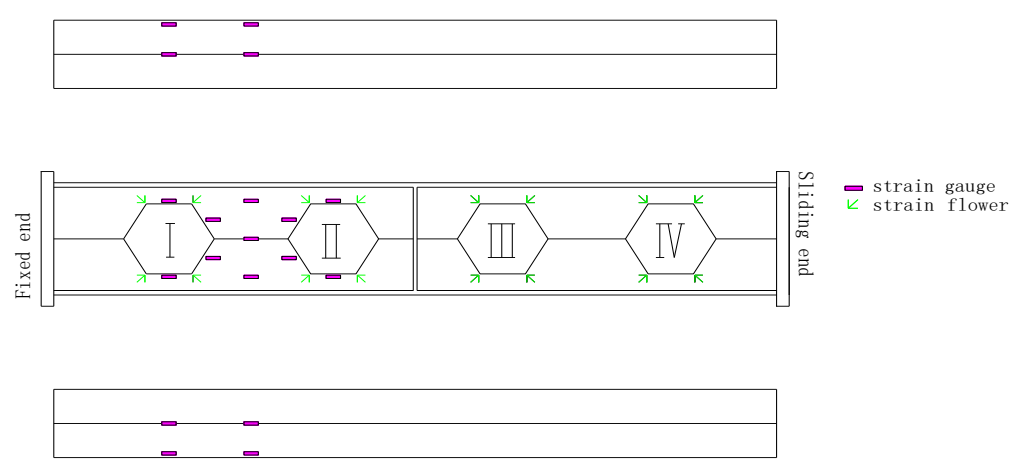

(a) Non-stiffened beam
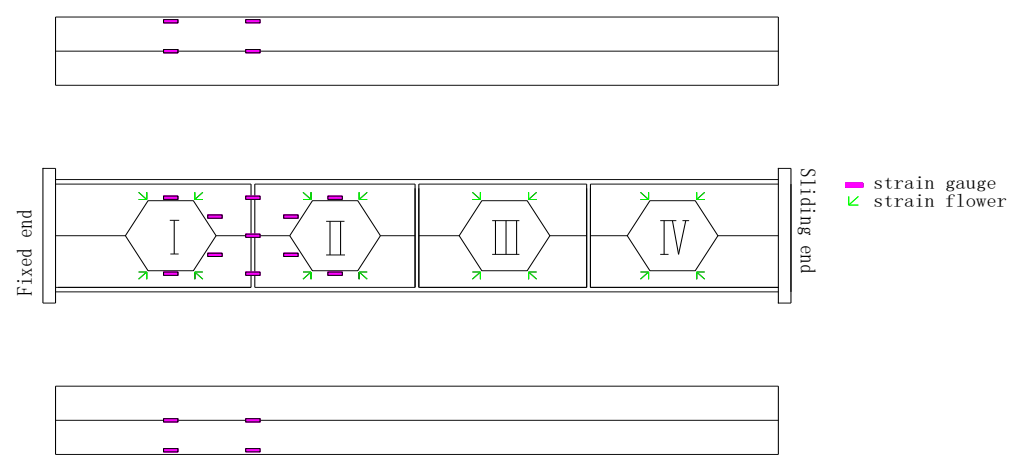

(b) Beam with transverse stiffening ribs

Fig. 8 Arrangement of the strain gauges and strain flowers

\section{Test results}

\subsection{Test phenomena}

According to Fig. 9, the final failure pattern of specimen FWL-240-75 is

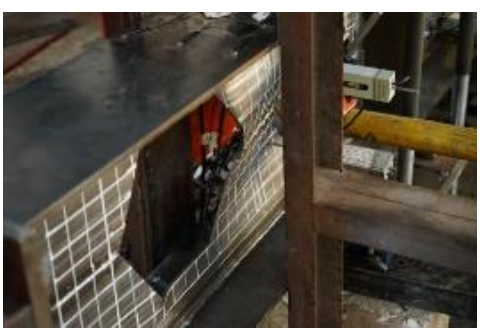

(a) Local buckling of the webs between the holes in the loading process

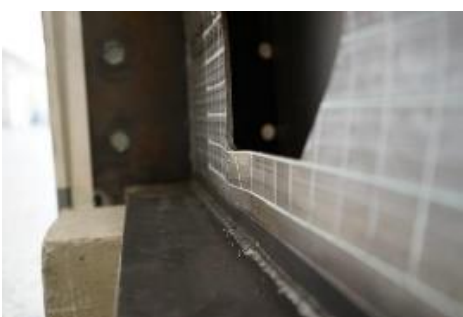

(c) Local buckling of hole angle No. 4 the S-shaped deformation of the webs, and the weld positions do not experience failure. Moreover, no tearing occurs in the hole angle, and the flange does not reach the yield state.

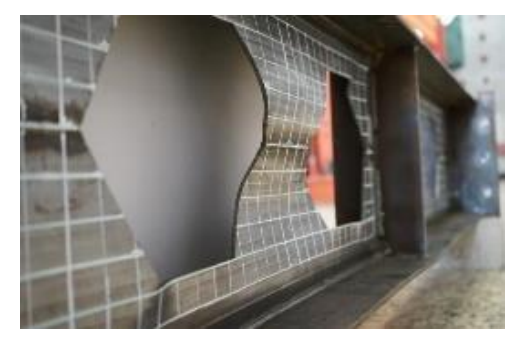

(b) Local buckling of the webs

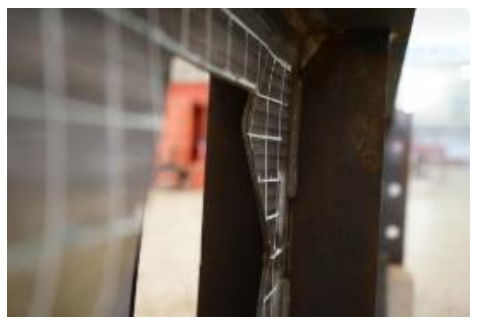

(d) Local buckling of hole angle No. 3

Fig. 9 Failure pattern of specimen FWL-240-75

As can be seen in Fig. 10, specimen FWL-240-85 suffers the local damage to the abdominal plate between the holes. The weld positions do not fail, and no tearing occurs in the hole angle. 


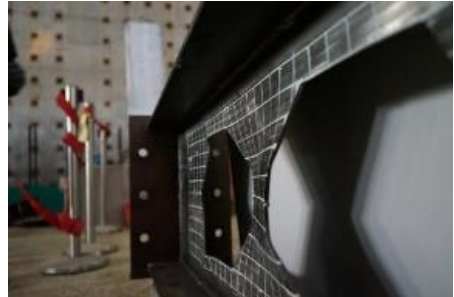

(a) Local buckling of the webs

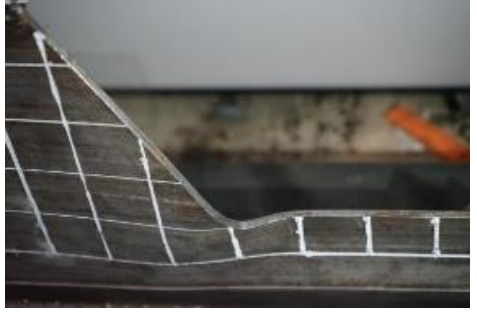

(b) Local buckling of the hole angle

Fig. 10 Failure pattern of specimen FWL-240-85

According to Fig. 11, depicting the final damage pattern of specimen JJFWL-240-75, each hole angle and hole circle experience different degrees of

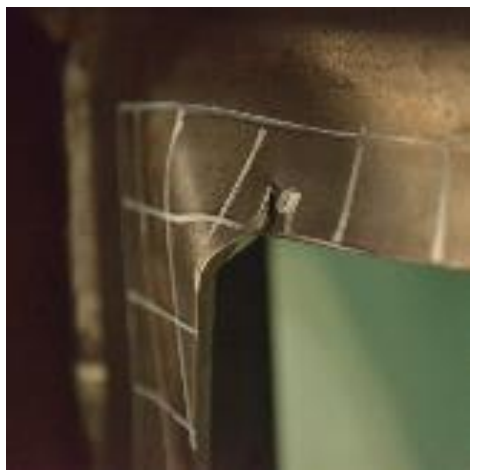

(a) Tearing in hole angle buckling, and hole No. 4 faces the most obvious buckling. Further, the weld positions have not been damaged, and the flange has not reached the yield state.

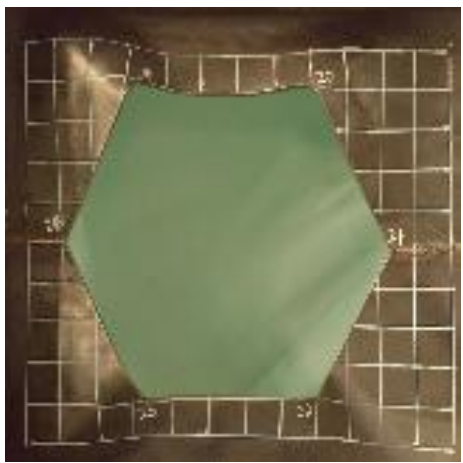

(b) IV failure

Fig. 11 Failure pattern of specimen JJFWL-240-75

Fig. 12. displays the final failure pattern of specimen JJFWL-240-85. It can be seen that different degrees of buckling occur at each hole angle and in the adjacent area. Also, the bearing capacity of the specimen is gradually decreased. When the lower area of I is yielding, the specimen is destroyed.
Damage to holes No. 1 and No. 4 is more serious, and the angle of hole No. 1 is torn, while the weld positions are not destroyed; moreover, the flange does not reach the yield state.

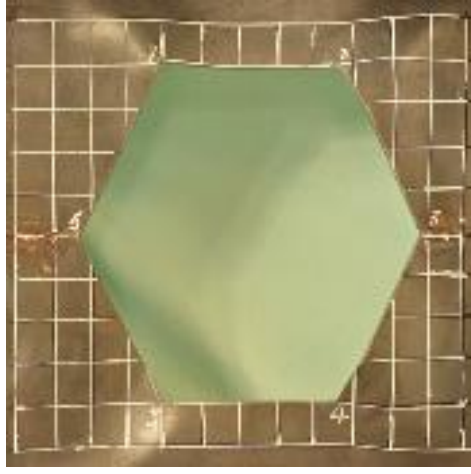

(a) Area near I failure

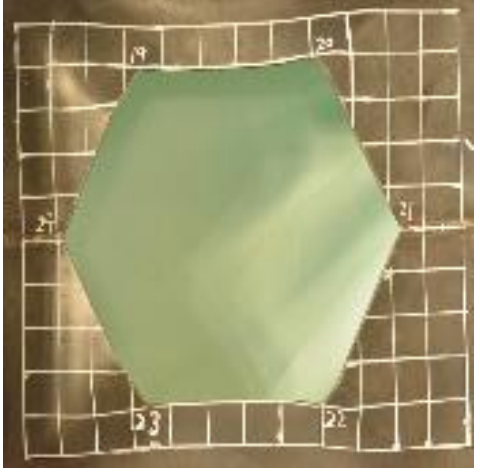

(b) Area near IV failure

Fig. 12 Failure pattern of specimen JJFWL-240-85

Comparing the failure patterns of the above specimens, we can conclude that:

- The main failure mode of specimens JJFWL-240-85 and JJFWL-240-75 is the buckling or tearing of the hole angle, which leads to a decrease in the bearing capacity of the beam. However, specimen JJFWL-240-75 only faces buckling of hole No. 4, but all the four hole angles of specimen JJFWL-240-85 suffer buckling with mutual symmetry.

- No obvious failure occurs between the flange of each specimen and the pier plate between the holes. They are restrained by the stiffening rib, and the pier of the hole no longer buckles. Therefore, the transverse stiffening rib can effectively prevent the pier plate from buckling.

\subsection{Performance analysis}

The hysteresis curves, skeleton curves, and the relations between the corresponding load and displacement of each specimen are presented in Fig. 13, Fig. 14, and Table 3 respectively.

Comparing the hysteresis curves of each specimen in Fig. 13 demonstrates that by setting up the transverse stiffening rib, each member has different degrees of pinch phenomenon; the pinch degree of the hysteresis curves of specimen JJFWL-240-75 is more obvious than that of specimen JJFWL-240-85 because the force applied to each hole of the latter is more uniform in each stage of loading, which leads to the symmetrical buckling of the hole angle. However, later in the loading stage, the hole angle of the end hole of the specimen experiences large buckling deformation, and the end hole is destroyed faster, which leads to a decrease in the energy dissipation ability and deformation ability of the specimen. 


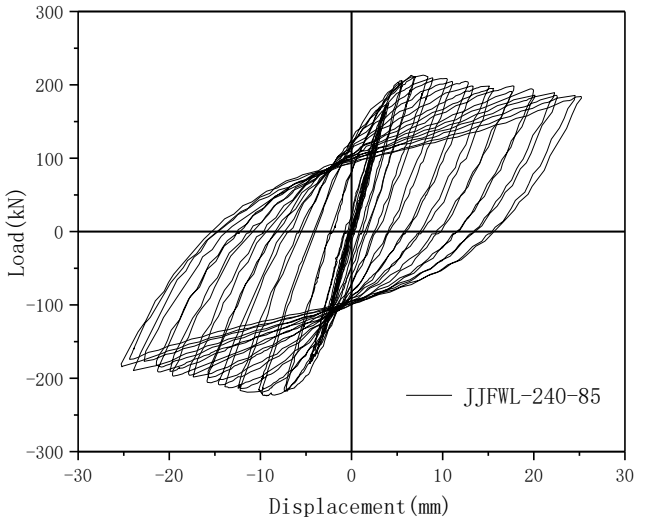

(a) JJFWL-240-75

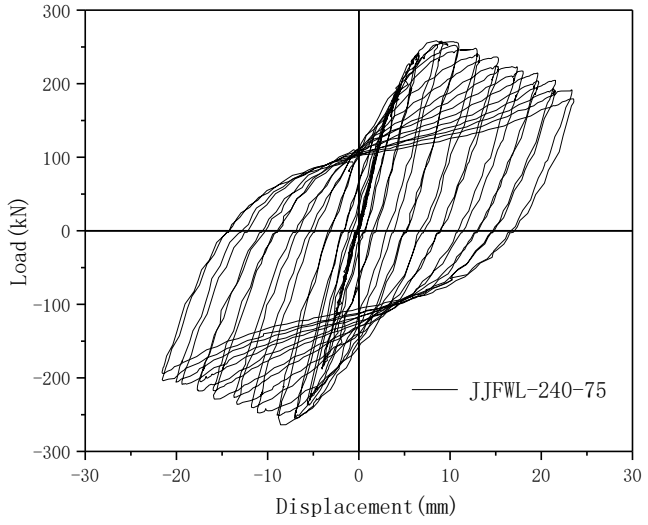

(b) JJFWL-240-85

Fig. 13 Hysteresis curves of the test specimens

The skeleton curves of the specimens in Fig. 14(a) and 14(b) show that the initial stiffness of the beam with transverse stiffening ribs slightly differs from that of the original specimen, and the load capacity and deformation capacity of the stiffened beam are increased. According to Fig. 14(c), the peak load of specimen JJFWL-240-75 is higher than that of specimen JJFWL-240-85; however, after the peak load, the decline in the curve of specimen JJFWL-240-85 is relatively flat, indicating that specimen JJFWL-240-85 has a better deformation ability.

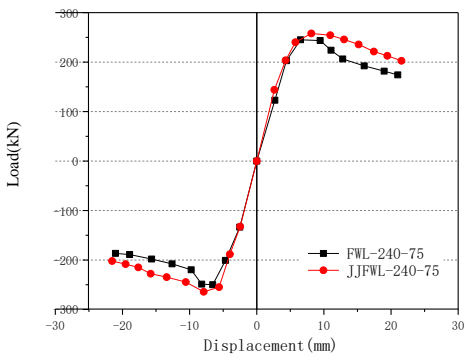

(a)FWL-240-75 and JJFWL-240-75

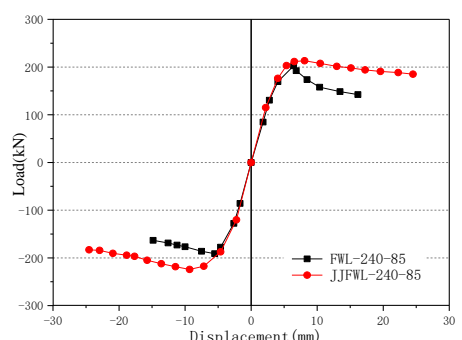

(b)FWL-240-85 and JJFWL-240-85

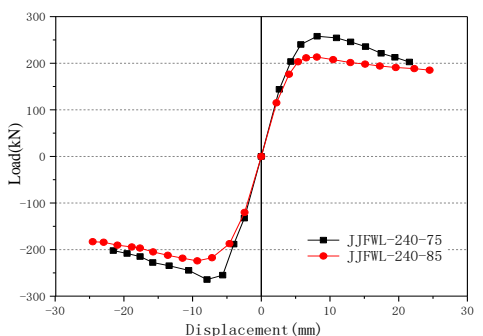

(c)JJFWL-240-75 and JJFWL-240-85

Fig. 14 Skeleton curves of the stiffened and non-stiffened test specimens

According to Table 3, comparing the peak load of the specimens shows that after setting up transverse stiffening ribs, the peak load of the specimen with a height-to-thickness ratio of 85 and the specimen with a height-to-thickness ratio of 75 increases by 8.4 and $2.9 \%$ respectively, which indicates that the transverse stiffener more obviously improves the bearing capacity of the specimen with a high thickness. Additionally, examining the yield displacement and the limit displacement reveals that after setting up the transverse stiffener, the yield displacement and limit displacement of the specimen with a height-to-thickness ratio of 85 improve by 78.14 and $180.18 \%$ respectively, while the yield displacement and limit displacement of the specimen with a height-to-thickness ratio of 75 increase by 38.31 and $64.83 \%$ respectively, which implies that setting up transverse stiffening ribs can greatly enhance the deformation ability of the specimen with a high thickness.

Table 3

The load and displacement of the specimens

\begin{tabular}{|c|c|c|c|c|c|c|}
\hline \multirow{2}{*}{ Beam ID } & \multicolumn{2}{|c|}{ Yield state } & \multicolumn{2}{|c|}{ Peak state } & \multicolumn{2}{|c|}{ Limit state } \\
\hline & $P_{y}$ & $\Delta_{y}$ & $P_{\max }$ & $\Delta_{\max }$ & $P_{u}$ & $\Delta_{u}$ \\
\hline FWL-240-75 & 208.06 & 3.68 & 250.75 & 6.56 & 213.12 & 10.89 \\
\hline FWL-240-85 & 151.79 & 2.79 & 202.19 & 5.73 & 183.54 & 7.72 \\
\hline JJFWL-240-75 & 222.74 & 5.09 & 258.16 & 10.63 & $219 . .44$ & 17.95 \\
\hline JJFWL-240-85 & 194.38 & 4.97 & 219.28 & 9.13 & 186.39 & 20.63 \\
\hline
\end{tabular}

\subsection{Strain analysis}

In this section, the strain variations of the hole angle and flange of the steel castellated girders are analyzed. The section of the specimen with transverse stiffening ribs between the pier plate does not have strain gauges; the location of the measurement points is shown in Fig. 15. 


\begin{tabular}{|lll|}
\hline $\mathrm{A} 1$ & $\mathrm{A3}$ & $\mathrm{A5}$ \\
$\mathrm{A} 2$ & $\mathrm{~A} 4$ & $\mathrm{A6}$ \\
\hline
\end{tabular}

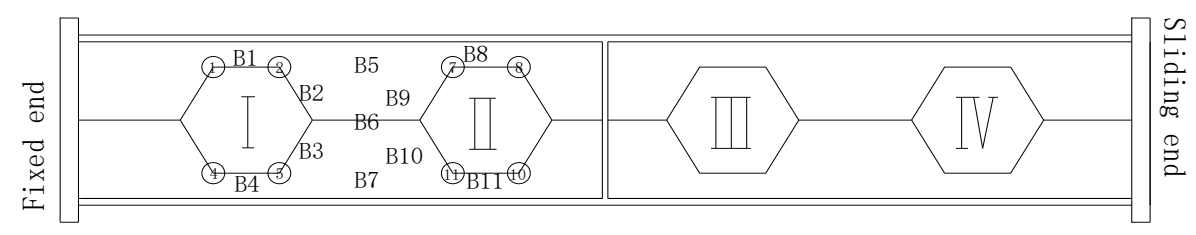

\begin{tabular}{|lll|}
\hline A8 & A10 & A12 \\
\hline A7 & A9 & A11 \\
\hline
\end{tabular}

Fig. 15 Location of the measurement points

\subsubsection{Strain analysis of flange}

All the specimens did not reach the yield state from the beginning of the loading to the destruction of the flange. To study the variation in the different sections of the flange, this section analyzes the strain on each specimen in the yield load, peak load, and the ultimate load states. The changes in the strain on the upper flange of each specimen are shown in Fig. 16.

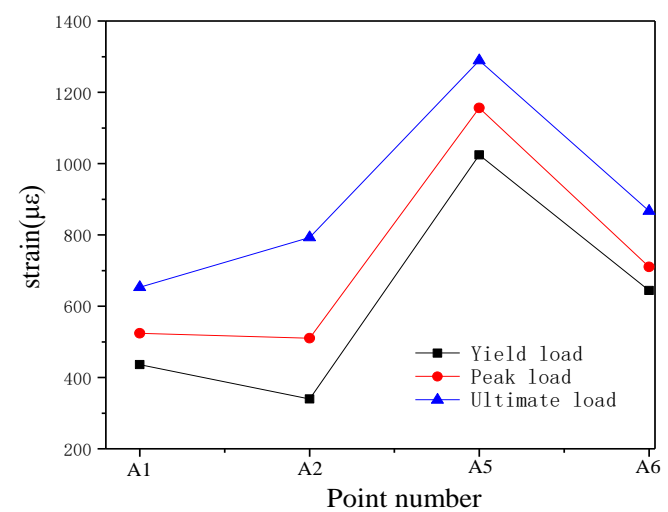

(a) JJFWL-240-75

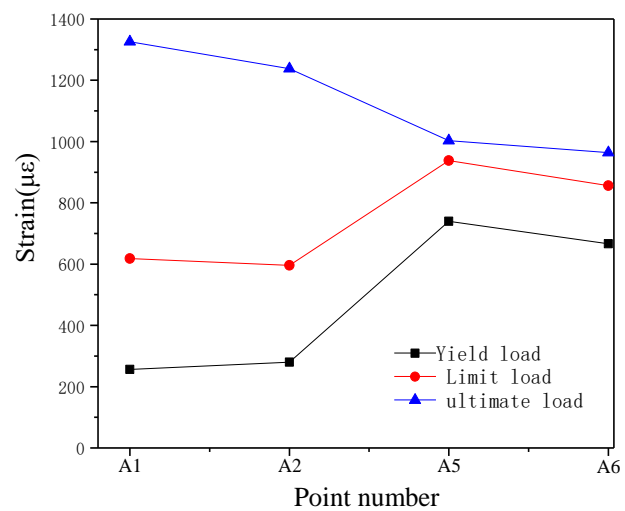

(b) JJFWL-240-85

Fig. 16 The changes of the strain on the upper flange of the test specimens

It is inferred from comparing the variation of the strain on the upper flange of each specimen in different states that when the yield load and peak load are reached, the variation trend in the strain on the flange of the two stiffened specimens with different height-to-thickness ratios is similar. Also, the strain on the flange of specimen JJFWL-240-85 is higher than that of specimen JJFWL-240-75. Nevertheless, at the limit load, the strain on the flange of specimen JJFWL-240-75 is higher than that of specimen JJFWL-240-85 because the buckling failure of the former reaches the limit load, and the stress is transferred from the hole angle to adjacent areas, which causes the shearing ability of the hole section to seriously decrease, and increases the strain on the corresponding flange.

\subsubsection{Strain analysis of steel castellated beams}

To investigate the influence of different height-to-thickness ratios on the strain on the hole angle of steel castellated girders, the strain on each specimen is analyzed by considering two groups of displacement, namely $2 \mathrm{~mm}$ elastic displacement and $6 \mathrm{~mm}$ elastoplastic displacement. The variation of strain at each test point is shown in Fig. 17.

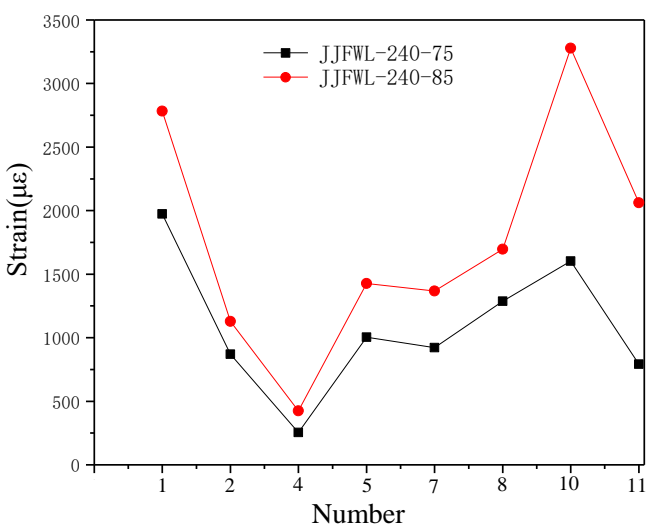

(a) $2 \mathrm{~mm}$ elastic displacement

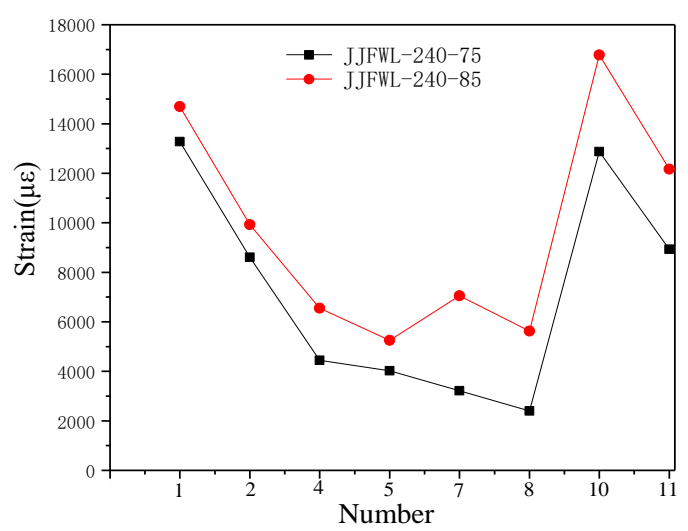

(b) $6 \mathrm{~mm}$ elastoplastic displacement

Fig. 17 The variation in the strain on the hole angle of the stiffened specimens

It can be inferred from Fig. 17 that as the height-to-thickness ratio of the webs increases, the stress concentration on the hole angle becomes more and 
more obvious. When the load displacement is set at $2 \mathrm{~mm}$, hole angles No. 1, 10 , and 11 of specimen JJFWL-240-85 yield, while only hole angle No. 1 of specimen JJFWL-240-75 yields. In the elastic-plastic stage, both hole angle positions reach the yield state.

\section{Establishment and verification of the finite element model (FEM)}

\subsection{Model description}

Global finite element (FE) analysis of the two full-scale castellated beams with stiffening ribs was conducted using ABAQUS 6.11 [17]. The aim of this global study is to compare and validate the model with experimental results and then perform a parametric study. Based on the beam geometry, a skeleton model was initially developed for each of the test specimens. Four-node shell elements (S4R) were used [18] so that the out-of-plane deformation of the honeycomb members can be easily observed under low-cycle reciprocating loads; similar finite element analyses can also be found elsewhere [19].

The built-in elastic-plastic model of ABAQUS, which is mainly utilized to simulate the elastoplastic properties of common metal materials, can be adopted for the steel beam, stiffener, and end plate. Its stress-strain relationship is based on a double broken line model which uses von Mises yield criterion. The model supposes that the flow potential surface function is the same as the yield function and assumes a tension and compression modulus of elasticity similar to the elastic modulus after steel yields, i.e. Es' $=0.01 \mathrm{Es}$, that is, the stress-strain relationship is still linear. The yield strength was based on the results of the material property testing, and the yield strength of steel with a thickness of 6 and $8 \mathrm{~mm}$ was considered to be 351.4 and $364.6 \mathrm{MPa}$ respectively as listed in Table 2 . The Poisson's ratio of the specimen was set at 0.3 , and according to the linear elastic properties of the material, the Young's modulus of steel with a thickness of 6 and $8 \mathrm{~mm}$ was equal to 208 and 198 GPa respectively. The finite element model of the steel castellated beam is illustrated in Fig. 18

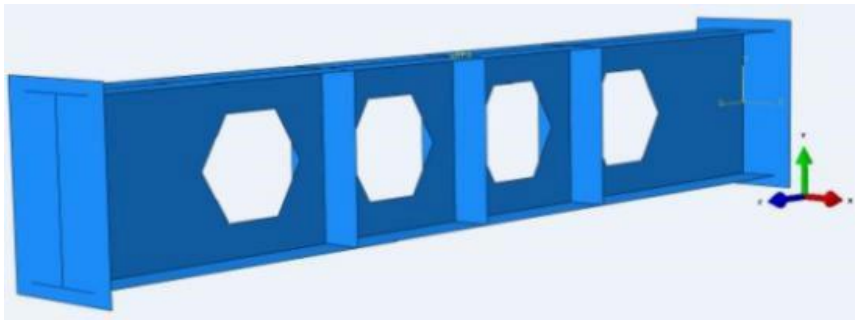

Fig. 18 Finite element model of the castellated beam

\subsection{Model interaction and boundary conditions}

During the processing of the specimen, the connection between the steel honeycomb beam and the stiffening rib is completed by welding, and each part of the member shows good cooperative working performance under the action of a low-cycle reciprocating load; also, the welded part does not show excessive relative movement. Therefore, in the process of ABAQUS modeling, in order to make the model achieve the good overall working performance of the components in actual tests, the "Merge" command in the "Assembly" module is adopted to merge the steel honeycomb beam and stiffener into a whole, and there is no definition of other interaction.

On the left end of the steel castellated beam model, we limit the displacement of $\mathrm{X}, \mathrm{Y}$, and $\mathrm{Z}$ and the rotation around the $Y$-axis and $Z$-axis so as to model the hinge support. On the right end of the beam, we limit $X$ and $Y$ displacement and the rotation around the $Y$-axis and $Z$-axis so as to simulate the sliding support. Additionally, we should limit the displacement of the upper and lower flange along the $X$-axis and the rotation around the $Z$-axis to model the lateral support.

In the process of the mesh division of the finite element model, the whole grid is divided first. To highlight the influence of the holes, the analysis is refined with a smaller meshing technique. The partitioned finite element model is depicted in Fig. 19

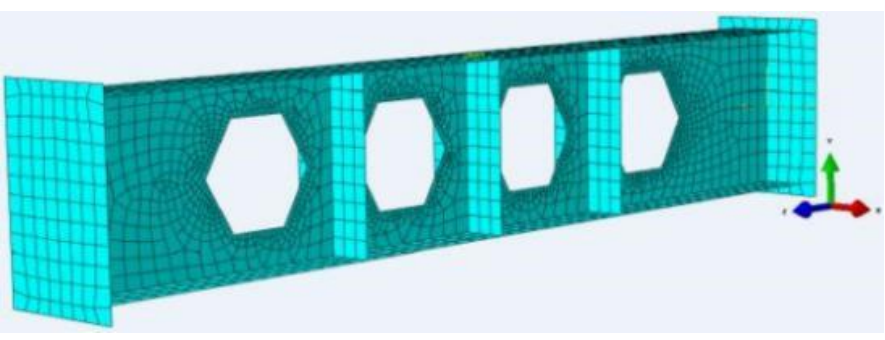

Fig. 19 Mesh division of the finite element model of the castellated beam

\subsection{Parameter verification of finite element model}

The finite element model is established according to the model establishment principle and the size of the specimen used in this experiment. Then, the yield displacement of each specimen is set to $\Delta$, and the method of displacement control loading is employed to load the different models in a low cycle. The loading mode is $0.5 \Delta, 1 \Delta, 1.5 \Delta, 2 \Delta$, etc. Next, the patterns of damage, hysteresis curves, and peak load of each model are obtained and compared with the test results. The accuracy of the model and its applicability to different conditions are verified, which lays the foundation for the simulation of different parameters.

\subsection{Comparison of failure patterns of the beams}

The damage to the hole angle is the failure mode of the specimen with different height-to-thickness ratios and the transverse stiffening ribs; the only difference is that specimen JJFWL-240-75 fails at hole number No. 4, while holes No. 1 and No. 4 of specimen JJFWL-240-85 are destroyed. Comparing the finite element simulation of the steel castellated beam with the experimental results (Fig. 20) reveals a similar failure mode and confirms that the simulation data well match the experimental results.

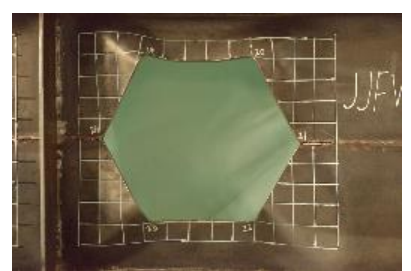

(a) Destruction of JJFWL-240-75

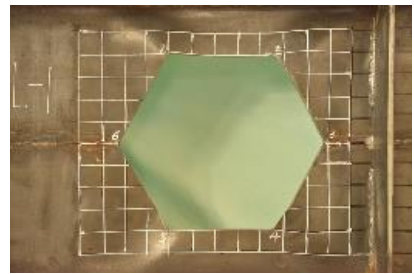

(c) Destruction of the left hole of JJFWL-240-85

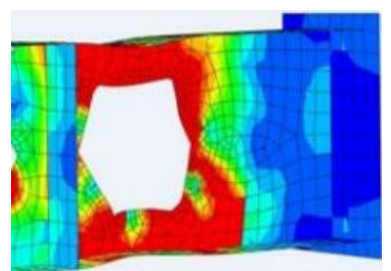

(b) Simulated destruction of JJFWL-240-75

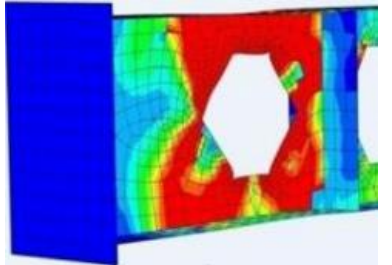

(d) Simulated destruction of the left hole of JJFWL-240-85 


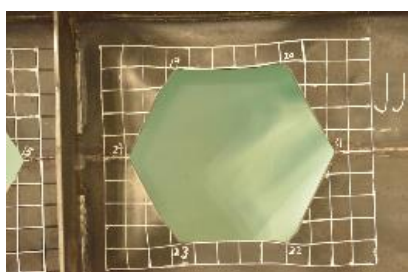

(e) Destruction of the right hole of JJFWL-240-85

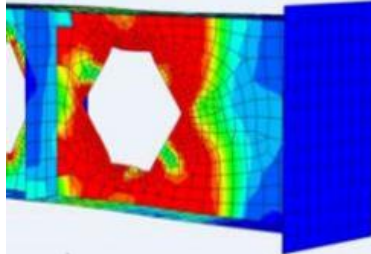

(f) Simulated destruction of the right hole of JJFWL-240-85

Fig. 20 Comparison of finite element data with the experimental results

\subsection{Comparison of hysteresis curves of the beams}

Fig. 21 presents the comparison between the experimental and simulated hysteresis curves of the castellated members. It can be seen that the finite element simulation is in good agreement with the experimentation. In initial loading, the hysteresis curves of the test member are extraordinarily full However, with an increase in the displacement load, the hysteresis curves display a pinch phenomenon because of the buckling of the pier plate and the failure of the hole angle.

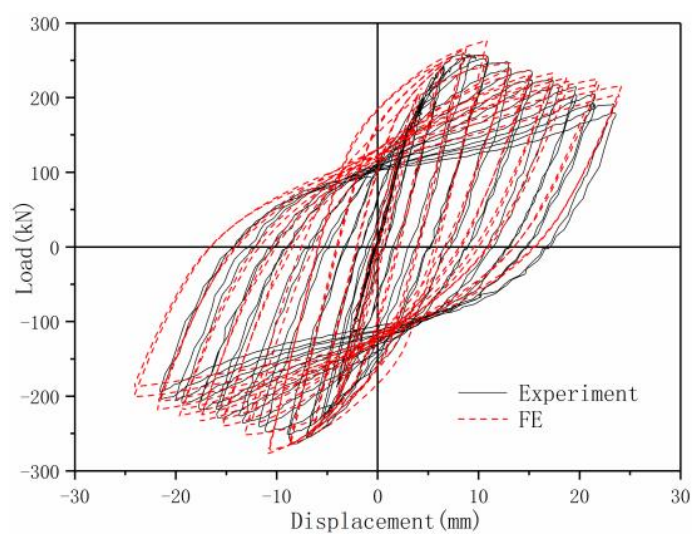

(a)JJFWL-240-75

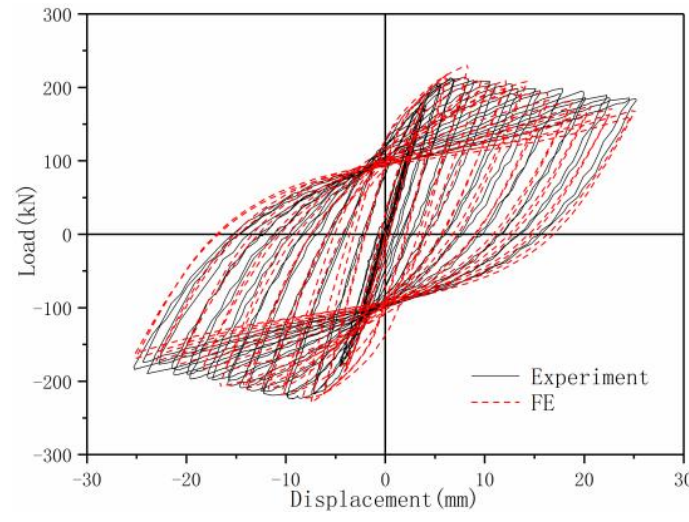

(b)JJFWL-240-85

Fig. 21 Comparison between the experimental and simulated hysteresis curves

\subsection{Comparison of the bearing capacity of the beams}

Table 4 shows that there is a slight difference of $6 \%$ between the experimental results and the finite element simulation data, which denotes that the finite element analysis is consistent with the experimental testing, so it can be used to perform a detailed study on the beams. In fact, by comparing the simulation results with the failure morphology, it is found that the data obtained from the finite element model well match the test results with a minor error. Thus, it can be concluded that the model established in this work is accurate enough to be utilized to further study the local stability and hysteretic performance of steel castellated girders under different conditions.

Table 4

Comparison of simulated and experimental ultimate bearing capacity of the beams

\begin{tabular}{ccccc}
\hline Beam ID & Experimental & $(\mathrm{kN})$ & Simulated & $(\mathrm{kN})$ \\
\hline JJFWL-240-75 & 258.16 & 273.63 \\
JJFWL-240-85 & 219.28 & 5.99 \\
4.15 & 228.38 \\
\hline
\end{tabular}

\section{FE analysis of the influence of different arrangements of stiffening} ribs on the hysteretic behavior of steel castellated beams

\subsection{Design of steel castellated beam with different arrangements of stiffeners}

Using the above finite element model, we set up different arrangements of stiffening ribs; the design parameters of the specimens are listed in Table 5. The section dimensions of the simulation member are the same as that of the test specimens, i.e. $400 \times 200 \times 5.1 \times 8$, and only the stiffener placement changes in the simulation. The other practical parameters are as follows: The height-to-thickness ratio of the web is 75 .

- The opening rate is $60 \%$.

- There are eight opened positive hexagonal holes.

- The beam length is $4200 \mathrm{~mm}$.

- The cross-medium stiffener thickness is $14 \mathrm{~mm}$.

- The transverse stiffener thickness is $6 \mathrm{~mm}$.

Specimen coding is done based on the component name and the stiffener arrangement position; taking JJFWL-2 as an example, "JJFWL" means steel castellated beam with transverse stiffener and " 2 " indicates the component sequence number. In the case of the stiffener layout positions, for example,
" 3113 " as the arrangement position code of the stiffening ribs denotes that eight honeycomb holes are separated by stiffening ribs according to three holes, one hole, one hole, and three holes.

\section{Table 5}

Design parameters of the arrangement of the stiffening ribs in the specimens

\begin{tabular}{ccccc}
\hline Beam ID & $\begin{array}{c}\text { Stiffening rib } \\
\text { position }\end{array}$ & $\begin{array}{c}\text { Opening } \\
\text { Number }\end{array}$ & $\begin{array}{c}\text { Opening rate } \\
(\%)\end{array}$ & $\begin{array}{c}\text { Web } \\
\text { height-to-thic } \\
\text { kness ratio }\end{array}$ \\
\hline JJFWL-1 & 44 & 8 & 60 & 75 \\
JJFWL-2 & 3113 & 8 & 60 & 75 \\
JJFWL-3 & 2222 & 8 & 60 & 75 \\
JJFWL-4 & 211112 & 8 & 60 & 75 \\
JJFWL-5 & 121121 & 8 & 60 & 75 \\
JJFWL-6 & 1331 & 8 & 60 & 75 \\
JJFWL-7 & 112211 & 8 & 60 & 75 \\
JJFWL-8 & 11111111 & 8 & 60 & 75 \\
\hline
\end{tabular}


5.2 Monotonic static loading analysis of steel castellated beams with different arrangements of stiffener

The load-displacement curves of the members are obtained by the monotonic static loading of the steel castellated beam with different arrangements of the stiffening ribs, as shown in Fig. 22. The yield displacement and yield load of the members are also listed in Table 6 .

According to Table 6 and Fig. 22, the yield displacement and yield load of the members are not very different. The initial stiffness difference is rather small, but the peak load, peak displacement, limit load, and limit displacement of the stiffened components obviously differ. After setting up the stiffener in different positions, the sequence of the local buckling of each member changes, so the load capacity of each component is different.

Table 6

Yield load and yield displacement under monotonic static loading

\begin{tabular}{ccc}
\hline Beam ID & Yield displacement $(\mathrm{mm})$ & Yield load $(\mathrm{kN})$ \\
\hline JJFWL-1 & 9.62 & 201.62 \\
JJFWL-2 & 10.11 & 210.38 \\
JJFWL-3 & 10.32 & 213.44 \\
JJFWL-4 & 10.51 & 218.62 \\
JJFWL-5 & 10.69 & 219.13 \\
JJFWL-6 & 11.12 & 221.75 \\
JJFWL-7 & 11.91 & 224.28 \\
JJFWL-8 & 12.31 & 226.67 \\
\hline
\end{tabular}

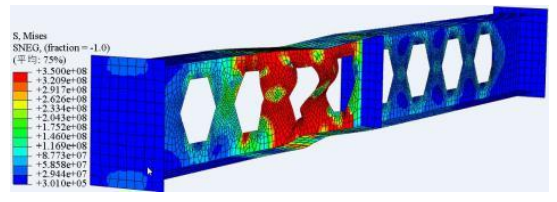

(a) JJFWL-1

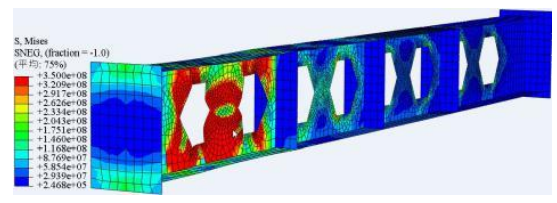

(c) JJFWL-3

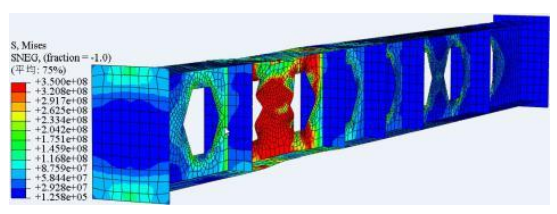

(e) JJFWL-5

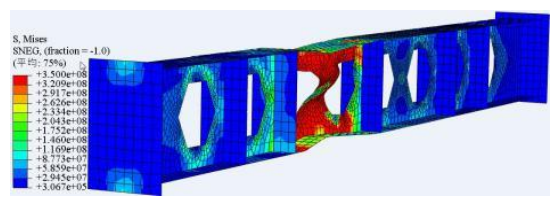

(g) JJFWL-7

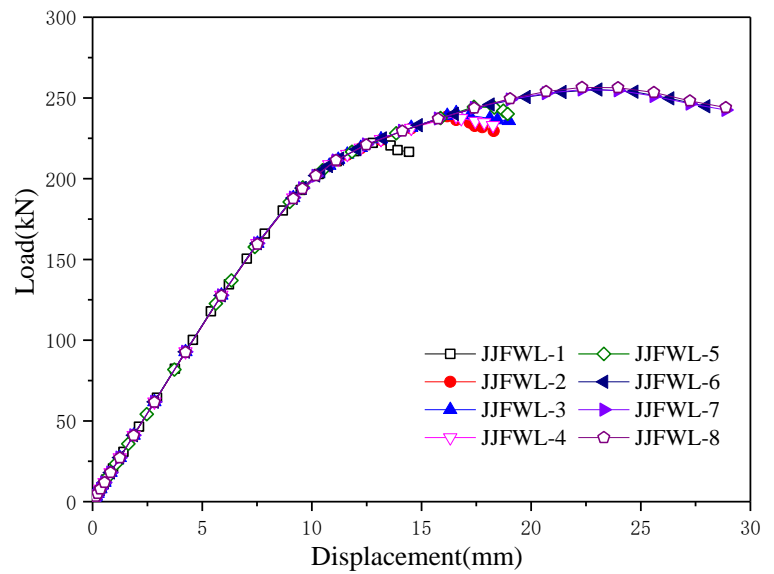

Fig. 22 Load-displacement relationship of the specimens

5.3. Hysteretic behavior analysis of steel castellated beams with different arrangements of stiffener

\subsubsection{Failure mode}

The failure patterns of the steel castellated beams with different arrangements of the stiffening ribs are illustrated in Fig. 23. Analyzing the simulation results of each component reveals that the S-shaped buckling occurs between the piers of specimens JJFWL-1, JJFWL-2, JJFWL-6, and JJFWL-7. However, specimens JJFWL-3, JJFWL-4, and JJFWL-5 fail due to the lateral torsion buckling of the holes between the piers and plates. Specimen JJFWL-8 suffers buckling damage to the flange and hole angle near the loading point, which indicates that the position of the stiffening rib is different, and the damage form or position of each member changes. It can be seen from the failure mode of each component that the local buckling mainly occurs in the area where the pier plate does not have a transverse stiffener. For specimen JJFWL-8, because the pier plate is arranged at the stiffener position, it does not buckle. Furthermore, the hole angle near the loading position first enters the yield state due to bearing the large bending moment and shear force, and then the strain is extended to the flange gradually. At the end, the hole section position forms a plastic hinge, and the specimen is destroyed.

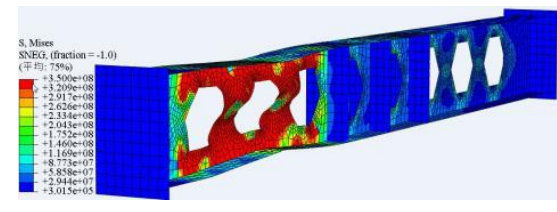

(b) JJFWL-2

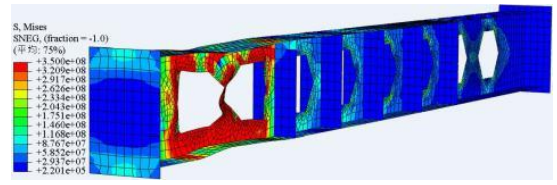

(d) JJFWL-4

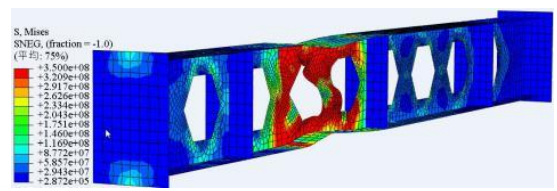

(f) JJFWL-6

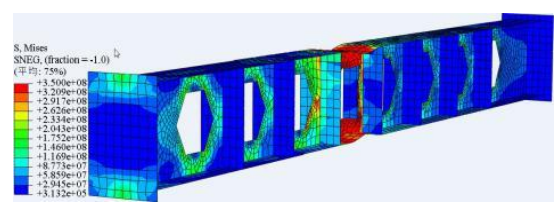

(h) JJFWL-8

Fig. 23 Stress cloud of the castellated beams with different arrangements of stiffeners 


\subsubsection{Hysteresis curves}

Fig. 24 delineates the hysteresis curves of the steel castellated beams with different arrangements of the stiffening ribs. Comparing the hysteresis curves of the members indicates that the hysteresis curves of the members are full regardless of the change in the position of the stiffeners, but the shrinkage

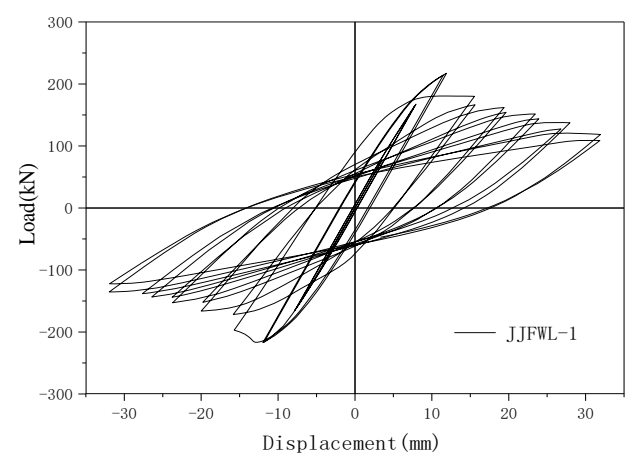

(a) JJFWL-1

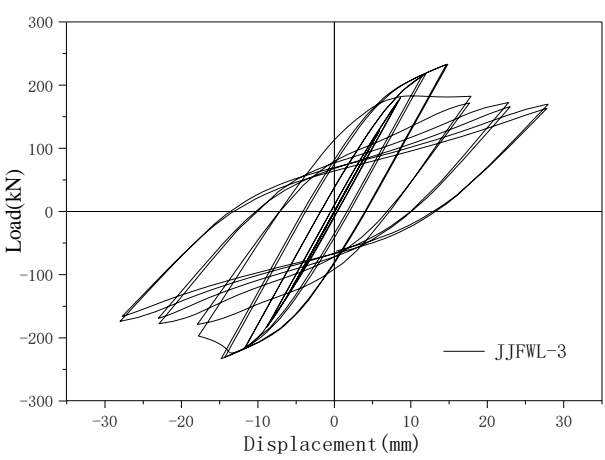

(c) JJFWL-3

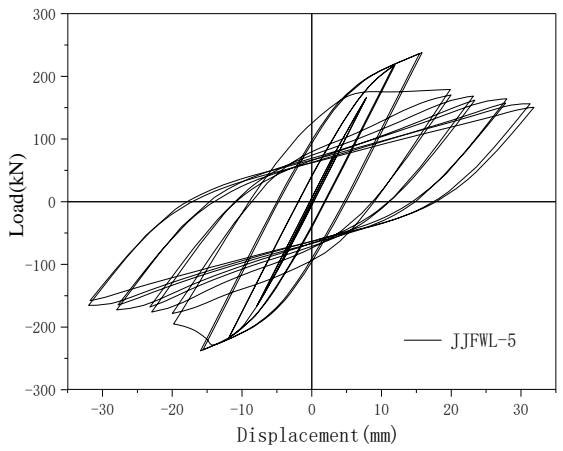

(e) JJFWL-5

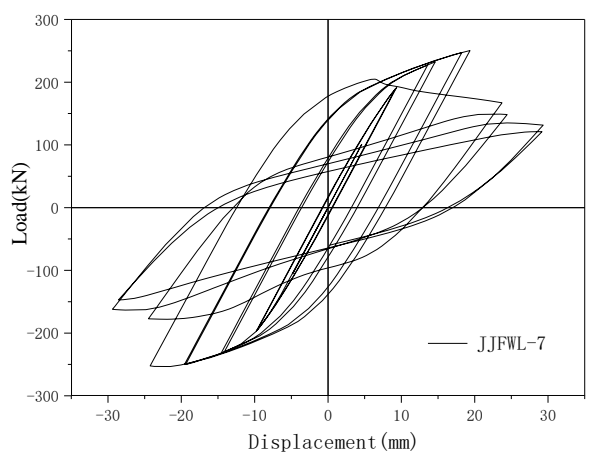

(g) JJFWL-7 phenomenon is different after the peak load. Specimen JJFWL-8 fails owing to the buckling of the hole near the flange, but the other members fail due to the buckling of some pier plates. The hysteresis loops of specimens JJFWL-7 and JJFWL-8 are fuller compared to the other members, so they have a higher energy dissipation capacity.

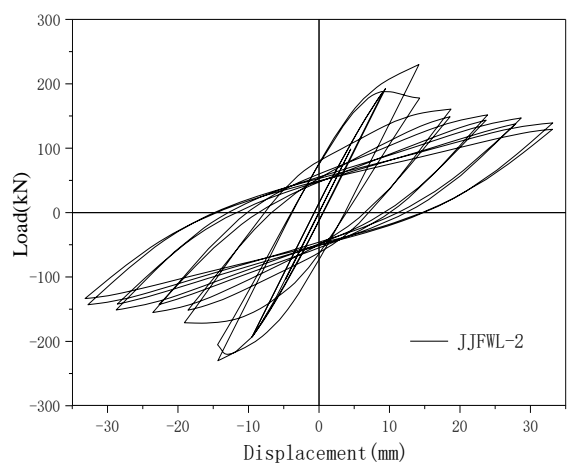

(b) JJFWL-2

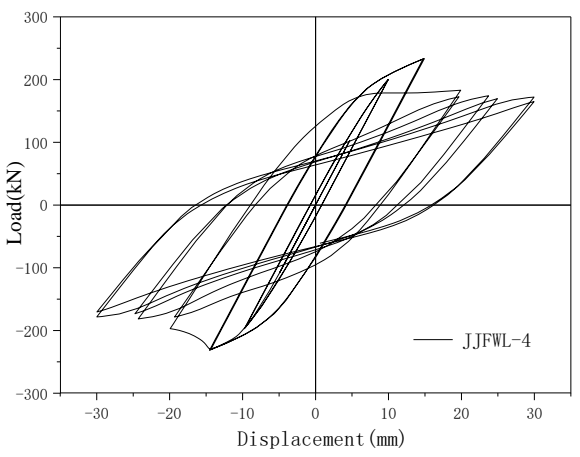

(d) JJFWL-4

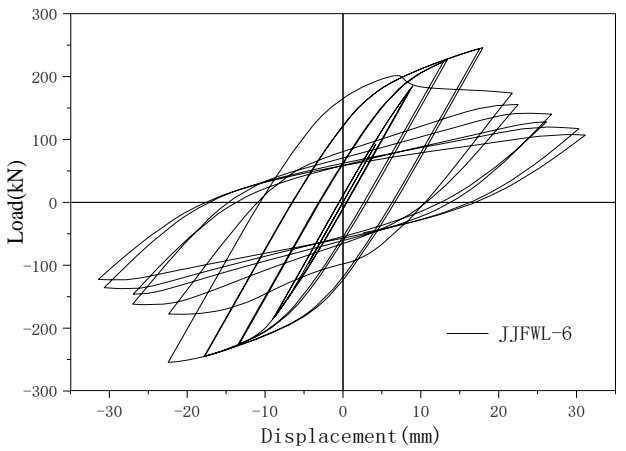

(f) JJFWL-6

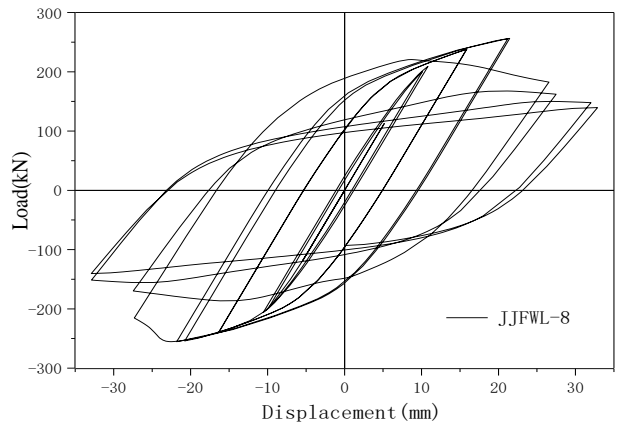

(h) JJFWL-8

Fig. 24 Hysteresis curves of the castellated beams with different arrangements of stiffeners

\subsubsection{Skeleton curves}

Fig. 25 draws the skeleton curves of the members with different arrangements of the stiffening ribs. According to Fig. 25 and Table 7, presenting the relationship between the load and displacement of the specimens, changing the placement of the stiffeners does not vary the initial stiffness of the members but raises their load capacity. The load capacity of specimen JJFWL-1 declines at first, which is attributed to the earlier buckling of the hole pier plate. Specimen JJFWL-8 has the highest load capacity and 
shows a gentler load drop compared to the other components. In all the arrangements of the transverse stiffening ribs, the web of specimen JJFWL-8 does not suffer buckling damage, so its bearing capacity is improved. As reported in Table 7, the peak load of specimens JJFWL-1, JJFWL-2, JJFWL-3, JJFWL-4, JJFWL-5, JJFWL-6, JJFWL-7, and JJFWL-8 is 216.42, 228.19, $233.49,233.53,237.08,251.14,253.15$, and $255.56 \mathrm{kN}$ respectively indicating a corresponding increase of 5.4, 2.3, 0.02, 1.5, 5.9, 0.8, and 0.95\% compared with the previous specimen. The difference in the bearing capacity of specimen JJFWL-1 and that of specimen JJFWL-8 is $39.14 \mathrm{kN}$, denoting an increase of $18.09 \%$, which indicates that the bearing capacity of the castellated members can be greatly improved by setting up transverse stiffeners. Nonetheless, it should be mentioned that the various arrangements of the stiffening ribs have different effects on the bearing capacity of the castellated members.

Table 7

The relation between load and displacement of the specimens

\begin{tabular}{|c|c|c|c|c|c|c|}
\hline \multirow{2}{*}{ Beam ID } & \multicolumn{2}{|c|}{ Yield state } & \multicolumn{2}{|c|}{ Peak state } & \multicolumn{2}{|c|}{ Limit state } \\
\hline & $P_{y}(\mathrm{kN})$ & $\Delta_{y}(\mathrm{~mm})$ & $P_{\max }(\mathrm{kN})$ & $\Delta_{\max }(\mathrm{mm})$ & $P_{u}(\mathrm{kN})$ & $\Delta_{u}(\mathrm{~mm})$ \\
\hline JJFWL-1 & 196.16 & 9.60 & 216.42 & 11.91 & 183.97 & 16.11 \\
\hline JJFWL-2 & 207.11 & 10.12 & 228.19 & 14.29 & 193.99 & 17.15 \\
\hline JJFWL-3 & 208.36 & 10.23 & 233.49 & 14.54 & 198.50 & 17.58 \\
\hline JJFWL-4 & 209.79 & 10.47 & 233.53 & 14.72 & 198.49 & 19.29 \\
\hline JJFWL-5 & 217.20 & 10.74 & 237.08 & 15.61 & 201.52 & 19.88 \\
\hline JJFWL-6 & 218.63 & 11.18 & 251.14 & 22.35 & 213.49 & 22.47 \\
\hline JJFWL-7 & 216.61 & 11.92 & 253.15 & 24.20 & 215.19 & 26.58 \\
\hline JJFWL-8 & 219.88 & 12.18 & 255.56 & 21.93 & 217.23 & 27.90 \\
\hline
\end{tabular}

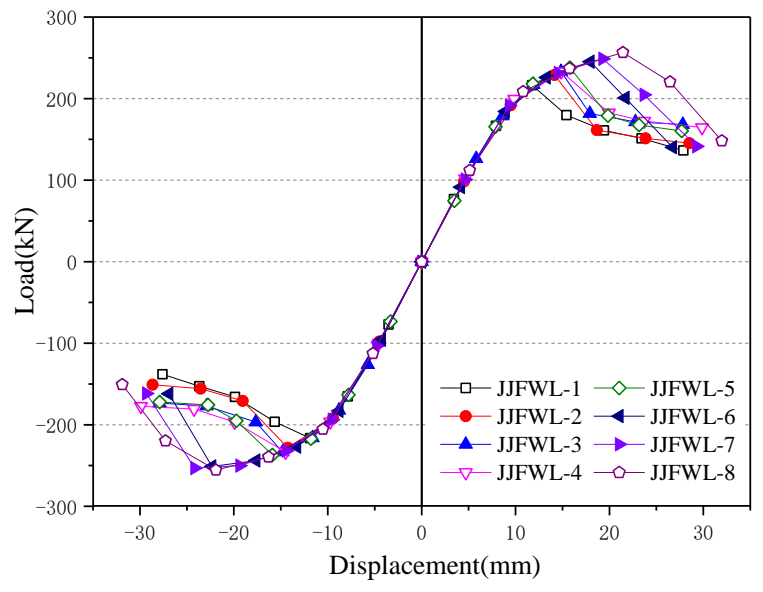

Fig. 25 Skeleton curves of the castellated beams with different arrangements of stiffeners

\subsubsection{Ductility}

The ductility coefficients of the castellated members with different arrangements of the stiffening ribs are listed in Table 8. It is clear that the ductility coefficient of the steel castellated girders is significantly affected by the different arrangements of the stiffeners and increases gradually by changing the position of the stiffeners. Specimens JJFWL-6, JJFWL-7, and JJFWL-8 have a higher ductility coefficient, and specimens JJFWL-7 and JJFWL-8 have a similar ductility coefficient of 2.23 and 2.29 respectively, differing only by $1.35 \%$.

\subsubsection{Energy consumption}

The energy dissipation coefficients and equivalent viscous damping coefficients of the members are presented in Table 9. Varying the placement of the stiffeners gradually raises the energy dissipation capacity of the members. The energy dissipation capacity of specimens JJFWL-7 and JJFWL-8 is 2.072 and 2.411 respectively, which demonstrates that the pier plates near the beam ends do not experience buckling failure, and the energy dissipation capacity of the steel castellated beams can be raised.
Table 8

The ductility coefficients of the specimens

\begin{tabular}{cccc}
\hline Beam ID & $\begin{array}{c}\text { Yield displacement } \\
(\mathrm{mm})\end{array}$ & $\begin{array}{c}\text { Limit displacement } \\
(\mathrm{mm})\end{array}$ & $\begin{array}{c}\text { Ductility } \\
\text { coefficient }\end{array}$ \\
\hline JJFWL-1 & 9.60 & 16.11 & 1.68 \\
JJFWL-2 & 10.12 & 17.15 & 1.69 \\
JJFWL-3 & 10.23 & 17.58 & 1.72 \\
JJFWL-4 & 10.47 & 19.29 & 1.84 \\
JJFWL-5 & 10.74 & 19.88 & 1.85 \\
JJFWL-6 & 11.18 & 22.47 & 2.01 \\
JJFWL-7 & 11.92 & 26.58 & 2.23 \\
JJFWL-8 & 12.18 & 27.90 & 2.29 \\
\hline
\end{tabular}

Table 9

The energy dissipation coefficients of the specimens

\begin{tabular}{ccc}
\hline Beam ID & $\begin{array}{c}\text { Equivalent viscous damping coefficients } \\
\left(h_{e}\right)\end{array}$ & $\begin{array}{c}\text { Energy dissipation } \\
\text { coefficients }(E)\end{array}$ \\
\hline JJFWL-1 & 0.184 & 1.152 \\
JJFWL-2 & 0.188 & 1.185 \\
JJFWL-3 & 0.238 & 1.149 \\
JJFWL-4 & 0.265 & 1.668 \\
JJFWL-5 & 0.267 & 1.678 \\
JJFWL-6 & 0.284 & 1.780 \\
JJFWL-7 & 0.329 & 2.072 \\
JJFWL-8 & 0.384 & 2.411 \\
\hline
\end{tabular}

\subsubsection{Stiffness degradation}

According to Fig. 26, presenting the stiffness degradation curves of the members with different arrangements of the stiffening ribs, the initial stiffness of the steel castellated girders with various arrangements of the stiffeners does not differ considerably. An increase in displacement load causes the stiffness degradation curves of specimens JJFWL-1, JJFWL-2, JJFWL-3, JJFWL-4, and JJFWL-5 to have a steep descending section, which shows that the corresponding arrangements of the transverse stiffeners have a negligible impact on the stiffness of the steel castellated girders. 


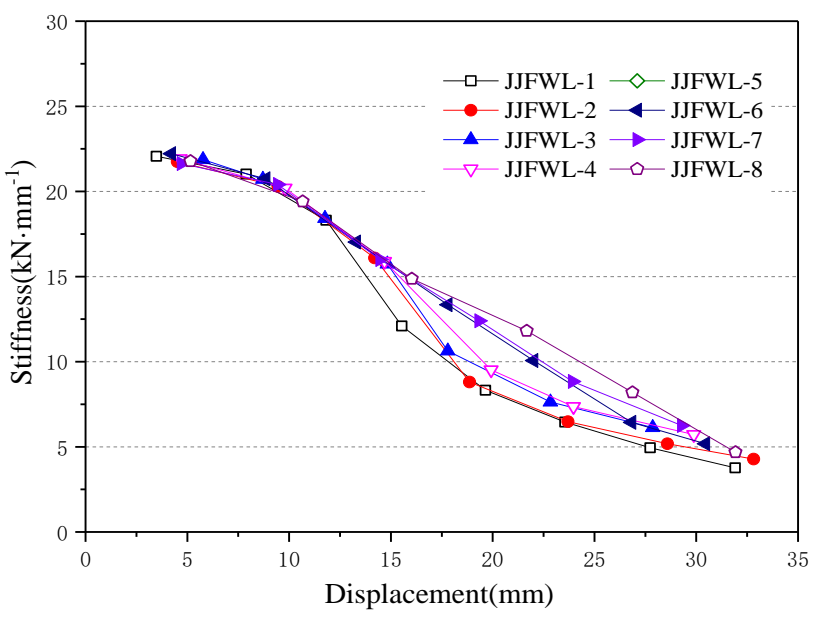

Fig. 26 Stiffness degradation curves of the castellated beams with different arrangements of stiffeners

In summary, through a comprehensive analysis of the different arrangements of the stiffening ribs of the steel castellated beam, we realized that setting up transverse stiffening ribs can greatly improve the hysteretic performance of steel castellated beams. Considering the practical application and engineering economy, a reasonable arrangement of stiffening ribs can effectively enhance the overall performance of the steel castellated girders. The stiffening ribs most obviously affect the first buckling position of the plate.

\section{Conclusions}

To study the hysteretic behavior of steel honeycomb beams with regular hexagonal holes, the impacts of different web height-to-thickness ratios, opening ratios, and arrangements of stiffening ribs on the seismic performance of steel honeycomb beams are studied by means of finite element analysis and experimentation. Based on the results obtained, the following conclusions can

\section{References}

[1] Sweden A.M.I., "Elastic Lateral Stability of I-shaped Cellular Steel Beams", Journal of Constructional Steel Research, 2011, Vol.67, No.2, pp.151-163.

[2] Tsavdaridis K.D. and D'Mello C.,"Web Buckling Study of the Behaviour and Strength of Perforated Steel Beams with Different Novel Web Opening Shapes", Journal of Constructional Steel Research, 2011, Vol.67, No.10, pp.1605-1620.

[3] Feng, R.;Zhan, H.;Meng, S.;Zhu, J."Experiments on H-shaped high-strength steel beams with perforated web",Engineering Structures,2018: 374-394.

[4] Li,X.H., et al."Experimental and Theoretical Study on the Behavior of the Steel-Concrete Composite Beam with Notched Web of Inverted T-shaped Steel Section at Construction Stage",Advanced Steel Construction: An International Journal,2011,Vol.7,No.4,pp.376-386.

[5] Huang B.S. et al., "Calculation method of equivalent bending stiffness of castellated beams and analysis of its influence factors", Journal of Building Structures, 2018, Vol.39, pp.121-127.

[6] Chen D.Y. and Pu W.L., "The Affection of Transverse Stiffener for Elastic Buckling of Castellated Beam Web Under Concentrated Load", International Journal of Science, 2016, Vol.3, No.5.

[7] Anupriya B., Jagadeesa K. and Baskar R., "Experimental investigation of shear strength of castellated beam with and without stiffeners", Journal of Structural Engineering, 2015, Vol.42, No.4, pp. 358-362.

[8] Jia,L.G., Liu,M. and Shi,W.X., "Analysis of the hysteresis performance of the frame node considering the buckling of castellated beam webs", Journal of SJZU University (natural Science Edition), 2016, Vol.6, pp. 961-969. be drawn:

(1) The larger the height-to-thickness ratio of the webs is, the more prone to local buckling the piers are. With the continuous increase of the reciprocating load, the damage accumulates gradually, and the local buckling becomes more and more serious. Moreover, when the components damage, the plastic development of the component is extremely inadequate, and the hysteretic performance is poor.

(2) Reinforcing the steel castellated beams with transverse stiffening ribs and binding the pier slab with the lateral stiffening rib plane effectively prevent the pier plate from buckling and notably improve the hysteretic performance of the beams compared to the non-stiffened steel castellated beams.

(3) Before the buckling of the steel castellated beams, there is little difference in the initial stiffness of the members with or without the transverse stiffening ribs. After buckling deformation, the bearing capacity and deformation ability of the members with the transverse stiffening ribs significantly improve. The larger the height-to-thickness ratio of the member is, the more significant the effect of the stiffening ribs becomes.

(4) The hysteretic performance of the steel castellated girders relates to the arrangement of the stiffening ribs. When the arrangement of the lateral stiffening ribs varies, the failure mode of the steel castellated beams changes. Furthermore, the seismic performance of the steel castellated beams changes when different arrangements of the stiffening ribs are used. However, using a larger number of stiffeners does not necessarily raise the hysteretic performance of the members. The impact of the stiffening ribs is most obvious at the first place where the buckling occurs.

\section{Acknowledgments}

This research work is supported by the National Natural Science Foundation of China (No. 51578346). The tests are conducted in Liaoning Key Lab on Structure and Material of Civil Engineering at Shenyang Jianzhu University. The support provided by the laboratory staff is gratefully acknowledged.

[9] Jia,L.G., et al., "Study on hysteresis performance of castellated beams", Journal of Architectural Science and Engineering, 2018, Vol.35, No.5, pp. 179-187.

[10] Jia L.G. et al., "Shear performance analysis of hexagonal hole castellated beam and castellated composite beam", Engineering Mechanics, 2016, Vol.33, No.1, pp. 81-87.

[11] Showkati H. et al., "Experiments on Elastically Braced Castellated Beams", Journal of Constructional Steel Research, 2012, Vol.77, No.10, pp. 163-172.

[12] Serror M., Hamed A. and Mourad S., "Numerical study on buckling of steel web plates with openings", Steel and Composite Structures, 2016, Vol.22, No.6, pp. 1417-1443.

[13] Pourbehi P. and Pirmoz A., "Shear response of castellated steel beams", International Journal of Steel Structures, 2015, Vol.15, No.2, pp. 389-399.

[14] Ministry of Construction, "Steel and steel products_ Location and preparation of test pieces for mechanical testing", Beijing, China, 1998.

[15] Ministry of Construction, "Metallic Materials-Tensile testing at ambient temperature", Beijing, China, 2010.

[16] Ministry of Construction, "Specification for seismic test of buildings", Beijing, China, 2015.

[17] ABAQUS Standard User's Manual, The Abaqus Software Is a Product of Dassault Systèmes Simulia Corp, Dassault Systèmes, Providence, RI, USA, 2008.

[18] Eiki Yamaguchi."Practical Finite Element Procedure for Achieving Mesh Objectivity in Local Buckling Analysis of Steel Structures by Beam Elements",Advanced Steel Construction: An International Journal,2009,Vol.5,No.3,273-288.

[19] Dong-Ho Choi,Nam-Il Kim."Inelastic Stability Analysis for Framed Structures Subjected to Non-conservative Forces",Advanced Steel Construction: An International Journal,2013,Vol.9,No.4,259-281. 